\title{
O SISU NA BERLINDA: PRESENTE E UMA PROVOCAÇÃO PARA O FUTURO
}

\author{
HUSTANA MARIA VARGAS ${ }^{*}$ \\ ORCID: https://orcid.org/0000-0002-0477-1246
}

RESUMO: Nossa "Palavra Aberta" sobre o Sistema de Seleção Unificada (SiSU) parte do seguinte ponto de vista: o sistema oferta e aloca de forma centralizada um bem extremamente valorizado: vagas em instituições públicas de educação superior. ${ }^{1}$ Como tal, supunha-se que os objetivos contidos em suas normativas fossem atingíveis de forma relativamente segura. Decorridos oito anos de sua implantação, não é o que se verifica. Do ponto de vista sociológico, não se trata propriamente de uma novidade, conforme enunciam Boudon, Merton e Giddens. Seriam os "efeitos não intencionais de ações intencionais" (HIGGINS, 2011, p.258), o que torna bastante relevantes as investigações sobre os malogros e desafios do sistema. Assim sendo, examinamos aqui algumas restrições e conflitos que afetam os agentes envolvidos no processo, e arriscamos, ao final, uma sugestão mais radical para os desafios atualmente verificados na implementação do sistema. A perspectiva que embasa essas reflexões advém da busca pela democratização da educação superior, fundamentada em preceitos de justiça social.

Palavras-chave: SISU. Acesso ao ensino superior. Democratização do ensino superior.

\section{SISU THROUGH THE WRINGER: ITS CURRENT STATE AND A PROVOCATION FOR THE FUTURE}

ABSTRACT:Our "Palavra Aberta" on the Unified Selection System (SiSU) starts from the following point of view: the system centrally offers and allocates an extremely valued asset: vacancies in public institutions of higher education. As such, it was assumed that the objectives contained in its regulations would be relatively safe to attain. Eight years after its implementation, this is not the case. From the sociological point of view, it is not really a novelty, as Boudon, Merton and Giddens state. These would be the "unintended effects of intentional actions" (HIGGINS, 2011, p.258), which makes investigations about the failures and challenges of the system very relevant.

I Universidade Federal Fluminense, Niterói, RJ, Brasil.

${ }^{*}$ Doutora em Educação pela PUC-RJ, Professora Associada I da Universidade Federal Fluminense - FEUFF e PPGE. Integrante do Grupo de Pesquisa do Laboratório sobre acesso e permanência na universidade LAP/UFF. E-mail:< hustanavargas@gmail.com>. 
Thus, we examine here some restrictions and conflicts that affect the agents involved in the process, and we risk, in the end, a more radical suggestion for the challenges currently encountered in the system's implementation. The perspective supporting these reflections comes from the search for the democratization of higher education, based on precepts of social justice.

Keywords: SISU. Higher education access. Democratization of higher education.

\section{VAGAS NA EDUCAC̄̃̃O SUPERIOR: UM BEM VALORIZADO SOCIALMENTE}

Qual seria o lugar da educação superior no Brasil? A taxa líquida de escolarização superior foi de 18,1\% em 2015 (MEC/INEP, 2014), quase a metade dos 33\% que se quer atingir pela meta 12 do Plano Nacional de Educação (PNE) ${ }^{2}$ em 2024. A restrição do acesso se reflete numa participação muito desigual, considerados níveis de renda. Num comparativo entre Argentina, Brasil e Chile, a taxa de participação dos estudantes no ensino superior do quintil mais pobre nos três países, em 2013 e 2014, é de 27,4\% no Chile, 21,6\% na Argentina e 5,4\% no Brasil. Por outro lado, a titulação superior afeta a mobilidade social: no Brasil, a recompensa econômica média para os indivíduos com educação superior é duas vezes maior do que para os que só possuem o ensino médio (VARGAS e HERINGER, 2017). Por último, comparando os retornos salariais dos egressos dos setores público e privado, de forma geral, os primeiros possuem vantagem sobre os últimos (CAVALCANTI, 2017).

Esse sistema passou por um processo de massificação nas últimas décadas, apoiado em políticas de expansão em paralelo com a adoção de ações afirmativas para o sistema público federal, culminando com a promulgação da Lei de Cotas. ${ }^{3}$ As novas vagas do ensino público federal continuavam concentradas nas capitais e nos grandes centros, o que ensejou a criação do Programa de Apoio a Planos de Reestruturação e Expansão das Universidades Federais ${ }^{4}$ (REUNI), que objetivava induzir o aumento de vagas nas instituições federais, com ênfase no turno da noite e em novas unidades fora dos grandes centros. Dessa forma, o número de matrículas mais que dobrou nas federais, indo de 670.180 matrículas em 2006 para 1.249.324 em 2016. Entretanto, a taxa de conclusão média das graduações presenciais nas universidades públicas foi de 45,9\% em 2016, indicando problemas mais complexos na implementação do sistema (INEP, 2017). 


\section{UM SISTEMA DE SELEC̣̃̃O CENTRALIZADO DE VAGAS PÚBLICAS}

Com intenção de melhor alocar as novas e preciosas vagas públicas, surge o Sistema de Seleção Unificada, instituído pelas Portarias Normativas 2/2010 e 21/2012 (BRASIL, 2010 e 2012). Tal sistema objetiva a redução dos gastos com a realização de exames de seleção descentralizados, a diminuição da ineficiência observada na ocupação das vagas, a democratização do acesso à educação superior pública e a ampliação da mobilidade geográfica estudantil. ${ }^{5}$

Desde sua implantação, o SiSU apresentou crescente adesão. Em sua primeira edição, 51 instituições aderiram ao sistema. Em 2018, foram cerca de 130. Sua sistemática prevê a apresentação, pelo candidato, da nota do Exame Nacional do Ensino Médio (ENEM) realizado no ano anterior ao pleito, em dias específicos quando o sistema é aberto. Nesse momento, o candidato ajusta sua nota ao curso e instituição desejados, podendo apontar duas opções de curso, na mesma ou em diferentes instituições. Após essa etapa, segue um jogo em que ele pode ser aprovado na primeira ou na segunda opção, pode desejar ficar em lista de espera ou não ser aprovado. Caso não tenha sido bem-sucedido na edição do início do ano, pode reapresentar a nota do ENEM no processo seletivo do meio do ano. ${ }^{6}$ Em qualquer caso, tendo sido aprovado, no momento seguinte deverá acessar a instituição que o aprovou para efetuar os procedimentos de matrícula. Muitos candidatos desconhecem essa regra e perdem suas vagas.

\section{ENCONTROS E DESENCONTROS DO SISTEMA}

Passadas várias edições do SiSU, contamos com um razoável acervo de trabalhos avaliativos sobre suas vantagens e desvantagens. ${ }^{7}$ Existe uma ambivalência nos resultados que sugere indagar, previamente: quais as vantagens e desvantagens e para quem, considerando-se como agentes principais as instituições e os candidatos ou graduandos? De qual ponto de vista?

Inicialmente destacamos as vantagens do SiSU sobre o vestibular, do ponto de vista do estudante. Como vimos, suas chances de ingresso dobram. Além disso, se malsucedido em suas opções preferenciais, pode optar, ainda na fase de inscrição, por outra carreira e nela ser bem-sucedido, enquanto, no vestibular, cada instituição elaborava sua prova e seus critérios de seleção, não permitindo o reaproveitamento ou realocação da nota do candidato. $\mathrm{Na}$ pior das hipóteses, o candidato pode concorrer ao SiSU no ano seguinte como no vestibular, sem nenhum prejuízo. 
Com relação às instituições, destacamos inicialmente, a crítica de Luz (2012) sobre o sistema avaliativo: por ser uma avaliação única, instauraria uma contradição, visto que não são consideradas características peculiares do sistema de ensino básico brasileiro em sua elaboração. A unificação da seleção, assim, seria incoerente em um país onde o ensino médio encontra-se qualitativamente muito diferenciado. Confirmando essa percepção, Machado e Szerman, (2016, p. 23), com base nos microdados do ENEM e do Censo de Educação Superior "percebem que as instituições que adotam o SISU passam a recrutar alunos que, em média, pontuam mais no ENEM. ${ }^{8}$ (...) Como as instituições públicas geralmente têm uma boa reputação, espera-se que a centralização aumente a competição e o sorting dos alunos admitidos". ' No tocante à promessa de maior inclusão social, Nogueira et al. (2017) demonstram que as mudanças pós-SiSU foram menores do que se esperava na Universidade Federal de Minas Gerais (UFMG), exceto pela elevação do número de estudantes oriundos de escolas federais dentre os egressos das escolas públicas, e também pela observação de mudanças, conforme os cursos considerados: enquanto em alguns a participação de egressos de escolas públicas se elevou de forma acentuada, em outros diminuiu.

Notocanteàocupaçãodevagas, oSiSU elevousignificativamente a não matrícula de candidatos convocados pela UFMG, gerando a necessidade de sucessivas chamadas. Da mesma forma, é identificada a evasão ${ }^{10}$ de um elevado percentual de alunos nos primeiros semestres dos cursos, embora parte desses volte à universidade em outros cursos, revelando a estratégia de mudança de curso propiciada pelo sistema. Estudos sobre evasão por áreas identificou que as áreas de Ciências Agrárias, Ciências Biológicas, Engenharias, Ciências Exatas e da Terra e Ciências da Saúde, tradicionalmente mais concorridas na Universidade Federal de Uberlândia (BARBOSA et al., 2017), apresentaram aumento significativos nos percentuais de alunos evadidos após o SiSU. O contrário ocorreu nas áreas de Ciências Humanas, Linguística, Letras e Artes e Ciências Sociais Aplicadas. Numa análise relacionada à seletividade e origem dos candidatos na Universidade Federal da Paraíba, Almeida et al. (2016) observouse que nos cursos mais seletivos, a taxa de evasão é mais elevada entre aqueles que não são naturais do estado, enquanto o inverso é observado nos cursos de menor concorrência. "No primeiro caso, isto pode ser um indício de que o aluno escolheu o curso desejado, mas não a instituição de sua preferência" (ALMEIDA et al., 2016, p. 22). Da mesma forma, Li (2016), ao investigar o perfil de ingressantes 
pelo SiSU entre 2006 e 2014 em nível nacional, aponta um aumento do número de estudantes que ingressaram em universidades de outro estado, principalmente nas carreiras mais concorridas. É ainda destacado o caso da Medicina, que chegou a ter, em universidades das regiões Norte e Nordeste, maioria de calouros de outros estados.

Nogueira et al. (2017, p. 26) sintetizam, para os achados da UFMG, algo que pode ser generalizado: "o fato é que a ampliação da não matrícula de convocados, o abandono por parte de estudantes dos primeiros períodos e a intensificação do movimento de mudança de cursos tornaram o processo de ocupação das vagas menos eficiente e estável, exatamente o contrário do que se esperava com o SiSU”. Entretanto, entendemos que os efeitos críticos aqui destacados não podem ser atribuídos isoladamente à sistemática do SiSU. Nonato (2018) evidencia, nesse caso, os diferentes ou combinados efeitos do ENEM, da Lei de Cotas e do próprio SiSU no novo desenho de ocupação de vagas nas universidades federais.

\section{AJUSTES GOVERNAMENTAIS EM REAC̣ÃO AOS EFEITOS OBSERVADOS}

Ao MEC não escapou a preocupação com esses efeitos. Em abril de 2016, baixou-se a Portaria Normativa 8, criando os Indicadores de Qualidade para a Educação Superior, com uma inovação: o "Indicador de Trajetória dos Estudantes de cursos de graduação - ITE", a ser calculado a partir do acompanhamento da trajetória dos discentes ingressantes. Esse seria composto pela taxa de permanência, de desistência e de conclusão, quando fosse o caso. Pela primeira vez, acompanhar a trajetória dos estudantes tornavase objeto das normativas ${ }^{11}$ de avaliação, implicando as instituições, que se obrigariam a diagnósticos e intervenção sobre essas trajetórias. Afastada a Presidenta em maio de 2016, o novo Ministro da Educação revogou a Portaria 8 como um dos primeiros atos de sua gestão.

Já o Instituto Nacional de Estudos e Pesquisas Anísio Teixeira (INEP) realizou levantamentos, com base no Censo de Educação Superior de 2010 a 2015, mostrando que entre os calouros de 2010, mais de 1.392.470 passaram por situações de instabilidades com a vida universitária (ÍNDICE, 2018). Entre as desistências, 58,3\% eram de alunos de instituições privadas e $44,7 \%$ da rede pública. Além disso, informou que cerca de $20 \%$ dos 329 mil estudantes que ingressaram no ensino superior nas instituições federais fizeram o ENEM novamente depois de se matricular no curso. Com esse estudo, em 2017, o INEP passou a oferecer em seu site dados sobre o fluxo da educação superior. ${ }^{12}$ Para a rede federal, os dados entre 2010 e 2014 
demonstram aumento nas taxas de desistência, saindo de 8,3\% em 2010 para 42,6\% em 2014. Utilizando esses dados para os cursos de Pedagogia da UFMG e da Universidade Federal Fluminense (UFF) em Niterói e em Angra dos Reis, verificamos que a taxa de desistência acumulada também aumenta de 2010 a 2015, em todos os casos. Entretanto, na UFF os dados são piores do que na UFMG, e piores ainda no interior, Angra dos Reis, do que em Niterói, unidade sede.

De tal sorte o problema das vagas ociosas tem se desenhado que o MEC anunciou, em setembro de 2018, a criação de um sistema informatizado para selecionar estudantes interessados em ocupar vagas remanescentes nas IFES. ${ }^{13}$ Inspirado no SiSU, o programa foi batizado de SiSU Transferência (MEC ANUNCIA, 2018).

\section{RECONFIGURANDO O PROBLEMA}

Estamos, assim, diante de um impasse, não de todo imprevisível quando se trata de políticas públicas ou de ação coletiva, na perspectiva dos já mencionados efeitos perversos da ordem social (HIGGINS, 2011, p.258). Na definição de Boudon, "trata-se de efeitos individuais ou coletivos que resultam da justaposição de comportamentos individuais sem que estes efeitos estejam entre os objetivos visados pelos autores" (BOUDON, 1979, p. 54). Nessa linha de análise, destacamos os agentes envolvidos no jogo. São múltiplos e com interesses, capacidades, possibilidades e estratégias variadas.

De um lado, temos as instituições públicas ofertantes. Cada qual com seu prestígio e seu rol de cursos, ofertados em certas localidades, aplicando pesos diferentes às notas dos componentes do ENEM e praticando ações afirmativas com alguma autonomia. Estas desejam o preenchimento total de suas vagas, com estudantes que concluam os cursos por sua boa qualificação acadêmica e identificação com o curso, com a instituição e com a localidade. Aqueles com déficits acadêmicos ou materiais, mas também identificados com o curso, com a instituição e com a localidade, podem acionar políticas de apoio acadêmico, social, psicológico e de saúde. Entretanto, esses ofertantes não gozam de autonomia plena, posto que se submetem ao orçamento e a legislações nacionais sobre educação.

De outro lado, temos os candidatos. Demandam as vagas com suas notas no ENEM, em cursos, instituições e localidades de sua preferência ou o mais próximo disso. O nível socioeconômico é o maior limitador de suas notas e escolhas, conforme vasta literatura (ARROYO, 1990; BARROS, 2001; FORACHI, 1977; VARGAS, 2008). Uma vez aprovado, temos agora o calouro, apresentando 
novos desafios. Seus julgamentos sobre curso, instituição e localidade ${ }^{14}$ se confirmam? Se se confirmarem, ele se adapta à nova experiência escolar? Seu desempenho acadêmico é suficiente para concluir o curso? E quanto ao nível socioeconômico? Se já foi marcante para sua realidade como candidato, será companheiro constante no decurso da graduação, pelas questões materiais e simbólicas envolvidas, pelos capitais acionáveis (BOURDIEU, 2012) e pelo processo de afiliação (COULON, 2008) mais ou menos facilitado, para citarmos alguns componentes dessa interação.

Percebemos, assim, que das instituições aos ingressantes e concluintes, a lista de condições aumenta. Entre ofertantes e demandantes, há convergência de interesses por princípio, mas a consecução dos objetivos de ambos depende de fatores pluricausais, que vão desde a disponibilidade das famílias proverem o prolongamento dos estudos de seus filhos ou da compatibilização entre trabalho e estudo do aluno, até as condições do mercado de trabalho, passando pelas questões mais idiossincráticas de adaptação e pelas geracionais. Dessa forma, a efetividade das políticas públicas não se compara a outros processos, como o de expansão fabril, onde, de forma singela, ao se constatar necessidade de aumento da produção, aumentam-se os insumos, multiplica-se a produção e atende-se à nova demanda.

\section{Uma lupa sobre alguns desses problemas}

Examinando mais de perto, acreditamos que algumas situações têm sido negligenciadas na avaliação desses problemas. Vamos apresentálas e em seguida considerar algumas "vias de saída" para as mesmas.

Do lado das instituições, um elemento complicador do ajuste entre oferta e demanda por vagas é a autonomia apenas relativa em relação à política de ações afirmativas a adotar. ${ }^{15}$ Sucede, pelo seu elevado valor na sociedade brasileira, que os embates políticos sobre a destinação das vagas do ensino superior federal ultrapassam fronteiras internas. Vale dizer: o tema transita numa abrangente e disputada zona de interesse da sociedade. Como exemplo, citamos o questionamento judicial das cotas raciais aplicadas pela Universidade de Brasília pelo partido Democratas, posteriormente confirmadas pelo Supremo Tribunal Federal. ${ }^{16}$ Dentro da mesma problemática, mas com decisão desfavorável à universidade, citamos o caso da UFF (VARGAS, 2016) que estabeleceu, pela Resolução 525/2015, o "critério de inclusão regional para acesso aos cursos de graduação presenciais localizados nos campi fora da sede", acrescentando 
10\% na nota do ENEM aos candidatos residentes e que cursaram integralmente o ensino médio em escolas dos Municípios do Estado do Rio de Janeiro listados na Resolução. ${ }^{17}$ Entretanto, a Defensoria Pública da União moveu Ação Civil Pública contra a universidade, que foi obrigada a recuar dessa disposição. Outra situação: de 2010 a 2012, a UFF vinha aplicando um tipo de bônus para estudantes egressos do ensino básico público apenas municipal e estadual, com base na superioridade da formação provida pelos estabelecimentos federais. Da mesma forma, a instituição foi impedida de manter essa prática, agora pelo advento da Lei de Cotas.

Nesse sentido, como "via de saída", entendemos que a autonomia das instituições quanto a regras sobre ações afirmativas deve ser exposta e debatida publicamente, uma vez que afeta diretamente o público que vão atrair e manter. ${ }^{18}$ Além disso, trabalhos que aprofundem a sistemática de ingresso, iluminando zonas de sombra sobre a operacionalização do processo, devem ser incentivados. Os achados de Nonato (2018), por exemplo, permitem vislumbrar possíveis ajustes na Lei de Cotas, dentre eles: exigir mais tempo no ensino básico em escolas públicas, impedir quem já tem uma graduação de concorrer por cotas, dividir a proporção de cotas por tipo de ensino médio público e considerar a hierarquia dos cursos nas análises.

Quanto às dificuldades dos candidatos com o sistema, e posteriormente suas dificuldades de permanência, acreditamos que: 1) as instituições deveriam entrar em contato e não aguardar o contato do candidato, na fase de manifestação de interesse, 2) ampliação exponencial de propaganda informativa sobre o SiSU, suas regras e possibilidades no ensino médio público e nos meios de comunicação de massa principais como televisão, rádio e internet, 3) apresentação de mecanismos de assistência estudantil de cada instituição no momento de inscrição na plataforma do SiSU, dado o peso da limitação socioeconômica na escolha do curso, instituição e localidade e depois, na permanência dos estudantes, ${ }^{19}$ 4) especificar análises sobre evasão pelo crivo de cursos, localidade, instituições e origem pública municipal, estadual ou federal -, também poderia trazer mais luz para o problema e 5) ajustar frequentemente as regras do sistema, de modo a conferir mais estabilidade e menor manipulabilidade ao mesmo. ${ }^{20}$

E no tocante à problemática das escolhas dos candidatos, acreditamos que para além da já mencionada busca pela adequação ao curso, instituição e localidade de interesse, o que aumenta a imprevisibilidade do jogo, outro elemento deve ser adicionado, sendo seu oposto: o desconhecimento do que se quer, pelo candidato ou graduando. Pela nossa experiência docente de trinta anos, crescem os relatos de 
alunos na segunda, terceira ou quarta tentativa de "se encontrar" em uma graduação, muitas vezes com trocas de áreas de conhecimento entre uma tentativa e outra. Nesse sentido, desde 1995 Ristoff chama a atenção para a necessária distinção entre evasão e mobilidade na educação superior, legitimando as ações de mobilidade dos estudantes:

Parcela significativa do que chamamos de evasão (...) não é exclusão mas mobilidade, não é fuga, mas busca, não é desperdício mas investimento, não é fracasso - nem do aluno nem do professor, nem do curso ou da instituição, mas tentativa de buscar o sucesso ou a felicidade, aproveitando as revelações que o processo natural de crescimento dos indivíduos faz sobre suas reais potencialidades. (1995, p. 56)

Talvez esse seja um traço geracional que se articula com elementos como: aumento da amplitude da oferta de cursos, trazendo mais opções e mais insegurança quanto à escolha; a transição para novas formas de trabalho, mais flexíveis; uma nova noção sobre fruição da vida, mais voltada para ganhos financeiros ou manejo de tempo do que por vocação, dentre outros. Nesse caso, as universidades estariam submetidas ao mesmo choque de gerações que as famílias e o mundo do trabalho estão experimentando. Porém, sua institucionalidade torna mais lento o processo de atualização perante a nova lógica desse público.

\section{INDO ALÉM}

Em minha tese de doutorado sobre democratização da educação superior, ${ }^{21}$ eu propunha um "indicador de democratização da educação superior - IDES" que guardava semelhança com o atual Indicador de Diferença entre os Desempenhos Observado e Esperado do ENADE - o IDD.

O IDES incluía variáveis socioeconômicas dos estudantes e seu desempenho na avaliação nacional, analisados pela chave de cursos, localidade e organização administrativa e acadêmica. Dentre outros, os resultados apontavam uma impermeável e perversa hierarquia de carreiras, onde os mais ricos cursavam cursos prestigiosos e os mais pobres, cursos menos prestigiosos. O objetivo da tese era muito mais evidenciar essa situação do que propor alternativas a essa cristalizada desigualdade, percebida especialmente nas instituições federais, à época.

Um membro da banca me fez um questionamento desconcertante: "a solução para isso não estaria no sorteio das vagas públicas"? Senti um misto de irritação e espanto, porque acreditava que tal solução jamais seria aceita, pelo desenho de nossa estratificação 
social e pelo papel jogado pela educação superior nessa dinâmica. Portanto, seria uma indagação impertinente e inócua..., mas que nunca saiu de minha cabeça.

Acredito hoje que visões filosóficas sobre justiça social devem ser acionadas para subsidiar a abordagem do processo de admissão até a conclusão na educação pública. Destaco o pensamento igualitarista, para o qual ações compensatórias deveriam ser adotadas, com atribuição diferenciada de recursos educativos, a fim de reequilibrar as desigualdades observadas em todas as etapas do processo educacional (WALTEMBERG, 2002). Penso que, de alguma forma, todas as ações aqui tratadas - ENEM/SiSU, Lei de Cotas - representam passos nessa direção. Todavia, eles têm apresentado tantos resultados indesejados que se as IFES pudessem, certamente sairiam do sistema. Mesmo as "vias de saída" apontadas oferecem apenas paliativos às políticas praticadas, mas não iriam à raiz do problema. Além disso, os efeitos das persistentes desigualdades ${ }^{22}$ quanto à inclusão mediante políticas públicas, além dos riscos quanto à viabilidade econômica de um processo com tantas vagas ociosas, nos recordam, como se diz entre nós, quanto ao problema da justiça social, que "o buraco é mais embaixo".

Assim, para além da tese igualitarista, convocamos inicialmente a ideia de uma intensificação da massificação do acesso, garantindose a permanência. Tal ação produziria mais justiça social, sem colidir com a possibilidade de manutenção de bons resultados acadêmicos. Um bom exemplo se materializa na seguinte notícia: "Beneficiários do Bolsa Família são medalhistas em olimpíadas de matemática". ${ }^{23}$ Nos últimos sete anos, 999 beneficiários do programa foram medalhistas. Esses estudantes conquistaram 1.288 medalhas: 93 de ouro, 234 de prata e 961 de bronze, além de 465 menções honrosas. Para o diretor-geral do Instituto de Matemática Pura e Aplicada, a Olimpíada se torna um instrumento para abrir oportunidades. "Para quem está no Bolsa Família, isso acaba sendo um instrumento de justiça social” (IMPA, 2018).

Também na educação superior passamos a encontrar estudantes beneficiados pelo Bolsa Família nas IFES. É o que aponta Vasconcelos (2015), em estudo sobre alunos pobres nos cursos mais seletivos da Universidade Federal do Acre, campus Cruzeiro do Sul: Enfermagem e Letras Espanhol. Neste universo, há um predomínio considerável de alunos que não trabalham e contam, juntamente com seus pais e irmãos, com uma renda familiar de até um salário mínimo, sendo que oito dos dez entrevistados da pesquisa sobrevivem com a ajuda do programa Bolsa Família.

Vemos, assim, que a ampliação da base do recrutamento, sem dúvida, pode produzir resultados acadêmicos e de justiça 
social muito desejáveis. Portanto, por que não o sorteio das vagas públicas? Inicialmente, sanearia uma distorção, ao incluir mais proporcionalmente à sua representação demográfica, estudantes do ensino básico público, em todos os cursos. Como forma de garantia de acompanhamento acadêmico, o sorteio poderia ser realizado após a aplicação de Exame em que os candidatos obtivessem uma nota mínima, conforme ocorre em institutos de aplicação de universidades, como a Universidade Federal do Rio de Janeiro. Outra condição poderia ser a indicação de um único curso e/ou instituição.

Para o sucesso desse modelo, políticas de assistência estudantil e de permanência sistemáticas e prioritárias são condição sine qua non e certamente menos onerosas que o custo da evasão. Almeida et al. (2016) estimam que o custo anual por diplomado tenha se elevado de $\mathrm{R}$ \$ 70.848,96 para $\mathrm{R} \$ 86.464,44$, considerado o aumento da evasão. E acrescentam: "considerando essas estimativas para o efeito-SiSU, um aluno diplomado no tempo certo ou com dois anos de atraso custaria para a sociedade, em média, respectivamente $\mathrm{R} \$ 345.857,80$ e R \$ 518.786,60” (ALMEIDA et al., 2016, p. 22). Também o ministro da Educação, em entrevista sobre o "SiSU Transferência", apontou que "estas vagas ociosas representam um verdadeiro desperdício de dinheiro público, que vem sendo acumuladas (sic) há anos» (MEC ANUNCIA, 2018). Sabendo-se de antemão que as IFES passariam a conter um quantitativo importante de estudantes mais pobres, deveriam se preparar financeira e academicamente para tal desafio.

Enquanto não temos a educação básica pública nem a estrutura econômica e social com que sonhamos, que tornaria mais equânime a disputa pela educação superior pública nos moldes em que está hoje configurada, dar oportunidade de ingresso a uma base mais ampla de candidatos, garantindo-lhes tanto maior afinidade com suas escolhas quanto sua permanência, nos aproximaria de uma real democratização do campus, contribuindo, assim, para ampliar o alcance da justiça social em nosso país.

\section{REFERÊNCIAS}

ALMEIDA, Aléssio Tony Cavalcante de; SIQUEIRA, Liédje Bettizaide Oliveira de; SILVA, Andrea Ferreira da; SOBRAL, Eryka Fernanda Miranda; ROCHA, Evandro Farias. Estratégia Safe Choice sob menor Incerteza e Alocação Ineficiente no Ensino Superior Brasileiro. In: Encontro Regional de Economia, 21. 2016, Fortaleza. Anais [...] Fortaleza: [s.n.], 2016.

ARIOVALDO, Thainara Cristina de Castro e NOGUEIRA, Cláudio Marques Martins. Nova forma de acesso ao ensino superior público: um estado do conhecimento sobre o Sistema de Seleção Unificada - SiSU. Revista Internacional de Educação Superior. Campinas, SP v.4 n.1 AOP jan./abr. 2018 
ARROYO, Miguel. A universidade, o trabalho e o curso noturno. Estudos e debates. Brasília. n. 17, 1990.

BARBOSA, João Paulo Gomes, PORTILHO, MIRANDA, Lucio Antonio, TAVARES, Gilberto Jose Marcelo. A adoção do SiSU e a evasão na Universidade Federal de Uberlândia. RIAEE - Revista Ibero-Americana de Estudos em Educação, v. 12, n. 2, p. 722-738, 2017.

BARDELLA, F. P.; SOTOMAYOR, M. Redesenho e Análise do Mercado de Admissão aos Centros de Pós-Graduação em Economia no Brasil à Luz da Teoria dos Jogos: Um Experimento Natural em Desenho de Mercados. Revista Brasileira de Economia, v. 68, n. 4, p. 425-455, 2014.

BARROS, Ricardo P. de e MENDONÇA, Rosane S. P. de. Os determinantes da desigualdade no Brasil. Texto para discussão $\mathbf{n}^{\mathbf{0}}$ 377. Rio de Janeiro, julho de 1995. 2001. Disponível em< http://www.ipea.gov.br/pub/td/1995/td_0377.pdf.> Acesso em 10 ago. 2018.

BOUDON, Raymond. Efeitos perversos e ordem social. Rio de Janeiro: Zahar, 1979.

BOURDIEU, Pierre. Os excluídos do interior. In: NOGUEIRA, Maria Alice e CATANI, Afrânio (Orgs). Escritos de Educação. Petrópolis, RJ: Vozes, 2012.

BRASIL. Ministério da Educação. Portaria Normativa MEC n. 2, de 26 de janeiro de 2010. Institui e regulamenta o Sistema de Seleção Unificado. Disponível em: <http://portal.mec. gov.br/index.php?option $=$ com_docman\&view $=$ download\&alias $=2704$-sisuportarianormat iva2\&Itemid=30192> . Acesso em 2 set. 2018.

. Ministério da Educação. Portaria Normativa MEC n. 21, de 5 de novembro de 2012. Dispõe sobre o Sistema de Seleção Unificada - SiSU. Disponível em: <http://www. sisu.furg.br/images/portaria21 mec.pdf>. Acesso em 2 set. 2018.

Lei 13.005/2014. Plano Nacional de Educação - PNE. Brasília, DF, 2014.

CARDOSO, Ana Carolina. G. e VARGAS, Hustana Maria. Invisíveis no campus: sobre a permanência de estudantes de pedagogia e de engenharia mecânica na universidade federal fluminense. In: Gabriela Honorato; Rosana Heringer. (Org.). Acesso e sucesso no ensino superior: uma sociologia dos estudantes. 1ed. Rio de Janeiro: 7Letras, 2015, v. 1, p. 182-201.

CAVALCANTI, Anapaula Regina. L. Retornos econômicos à educação superior: Cursos, qualidade da instituição, desempenho acadêmico e implicações sobre a escolha de carreiras. Orientadora: Maria Eduarda Tannuri-Pianto. 2017. 109 f. Tese (Doutorado em Economia) - Faculdade de Economia, Administração, Contabilidade e Gestão de Políticas Públicas, Universidade de Brasília, Brasília, 2017.

COULON, Alain. A condição de estudante. A entrada na vida universitária. Salvador: EdUFBA, 2008.

FORACCHI, Marialice M. O estudante e a transformação da sociedade brasileira. São Paulo: Companhia Editora Nacional. 1977.

HIGGINS, Silvio S. O estudo dos efeitos não intencionais da ação intencional na teoria sociológica. Sociologias. Porto Alegre, ano 13, no 28, set./dez. 2011, p. 258-282.

IMPA. Em O Globo, histórias de medalhistas da OBMEP. Disponível em < https://impa.br/ page-noticias/em-o-globo-historias-de-medalhistas-da-obmep/>. Acesso em 12 set. 2018. 
ÍNDICE de troca ou abandono de curso em faculdades equivale à metade dos ingressantes. 2018. Disponível em <https://www.em.com.br/app/noticia/especiais/ educacao/2018/07/17/internas_educacao,973969/indice-de-troca-ou-abandono-de-cursoem-faculdades-equivale-a-metade-d.shtml>_Acesso em 2 set. 2018.

INEP. Metodologia de Cálculo dos Indicadores de Fluxo da Educação Superior. 2017. Disponível em <http://download.inep.gov.br/informacoes_estatisticas/indicadores_ educacionais/2017/metodologia_indicadores_trajetoria_curso.pdf > . Acesso em 9 set. 2018.

Indicadores educacionais. Disponível em http://portal.inep.gov.br/indicadoreseducacionais. Acesso em 9 set. 2018.

. Censo da Educação Superior 2016. 2017. Disponível em < https://abmes.org.br/ arquivos/documentos/apresentacao_censo_educacao_superior.pdf > . Acesso em 9 set. 2018.

LI, Denise Leyi. O Novo ENEM e a plataforma SiSU: efeitos sobre a migração e a evasão estudantil. Orientador: André Luis Squarlze Chagas. 2016. 108 f. Dissertação (Mestrado em Ciências) - Faculdade de Economia, Administração e Contabilidade, Universidade de São Paulo, São Paulo, 2016.

LUZ, Jackeline Lourenço Noronha da. O Sistema de Seleção Unificada (SiSU) na Universidade Federal de Mato Grosso - campus Cuiabá - e a relação com a democratização do acesso. In: PAULA, Maria de Fátima Costa de; SILVA, Maria das Graças Martins da. (Org.). As políticas de democratização da educação superior nos estados do Rio de Janeiro e de Mato Grosso. 1ed. Cuiabá: EduUFMT, 2012.

MACHADO, Cecília e SZERMAN, Christiane. Centralized Admission and the StudentCollege Match. No 10251, IZA Discussion Papers, Institute for the Study of Labor (IZA), 2016.

MEC ANUNCIA 'Sisu Transferência' para tentar ocupar as vagas remanescentes nas universidades federais. Disponível em < https://g1.globo.com/educacao/guia-de-carreiras/ noticia/2018/09/20/mec-anuncia-sisu-transferencia-para-tentar-ocupar-as-vagasremanescentes-nas-universidades-federais.ghtml>._Acesso em 9 set. 2018.

MORAIS, Adrielly R. Curso Pré-vestibular popular do Centro de Estudos e Ações Solidárias da Maré - CEASM: desafios múltiplos na confluência de práticas curriculares. Orientadora: Hustana Maria Vargas. 2016. Dissertação (Mestrado em Educação) - Faculdade de Educação, Universidade Federal Fluminense, Niterói, 2016.

NOGUEIRA, Cláudio Marques Martins; NONATO, Bréscia; RIBEIRO, Gustavo Meirelles; FLONTINO, Sandra Dantas. Promessas e Limites: o SiSU e sua implementação na Universidade Federal de Minas Gerais. Belo Horizonte: Educação em Revista [online]. 2017, vol. 33. Disponível em: < http://www.scielo.br/pdf/edur/v33/1982-6621-edur33-e161036.pdf>. Acesso em 22 set. 2018.

NONATO, Bréscia França. Lei de cotas e SISU: análise dos processos de escolha dos cursos superiores e do perfil dos estudantes da UFMG antes e após as mudanças na forma de acesso às instituições federais. Orientador: Claudio Marques Martins Nogueira. 2018. 300 f. Tese (Doutorado em Educação) - Faculdade de Educação, Universidade Federal de Minas Gerais, Belo Horizonte, 2018.

OBSERVATÓRIO do PNE. Disponível em <http://www.observatoriodopne.org.br/ metas-pne/12-ensino-superior>, 2018. Acesso em 12 set. 2018. 
RISTOFF, Dilvo. Evasão: exclusão ou mobilidade. Santa Catarina, UFSC, 1995 (mimeo).

SACCARO, Alice. Ampliação do ensino superior brasileiro: um estudo sobre as causas da evasão e o impacto da Bolsa Permanência do PNAES. Orientador: Marco Túlio Aniceto França. 2016. 72 f. Dissertação (Mestrado em Economia do Desenvolvimento) - Faculdade de Administração, Contabilidade e Economia, Pontifícia Universidade Católica do Rio Grande do Sul, Porto Alegre, 2016.

VASCONCELOS, Adriana Martins de Oliveira. Alunos pobres nos cursos mais seletivos da Universidade Federal do Acre, Campus Floresta. Orientadora: Hustana Maria Vargas. 2015. Dissertação (Mestrado em Educação) - Faculdade de Educação, Universidade Federal Fluminense, Niterói, 2015.

VARGAS, Hustana Maria. Interiorização da educação superior pública no Brasil: pontos de atenção, ajustes e autonomia universitária. Revista de Estudios Brasileños, v. 3, p. 156$169,2016$.

Represando e distribuindo distinção: a barragem do ensino superior. Orientadora: Zaia Brandão. 2008. 230 f. Tese (Doutorado em Educação) Departamento de Educação. Pontifícia Universidade Católica do Rio de Janeiro, Rio de Janeiro, 2008.

VARGAS, Hustana Maria; HERINGER, Rosana. Políticas de permanência no ensino superior público em perspectiva comparada: Argentina, Brasil e Chile. Arquivos analíticos de políticas educativas / education policy analysis archives, v. 25, p. 72, 2017.

WALTEMBERG, Fábio Domingues. Análise econômica de sistemas educativos. Uma resenha crítica da literatura e uma avaliação empírica da iniquidade do sistema educativo brasileiro. Orientador: Antônio Carlos Coelho Campino. 2002. 159 f. Dissertação (Mestrado em Economia) - Faculdade de Economia, Administração e Contabilidade, Universidade de São Paulo, São Paulo, 2002.

\section{NOTAS}

${ }^{1}$ Municipais, estaduais e federais. As federais abrigam o maior contingente de matrículas entre as públicas.

${ }^{2}$ Lei 13.005/2014. A meta 12 trata da educação superior.

${ }^{3}$ Lei 12.711/2012, alterada em 2016 pela Lei 13.409, que incluiu pessoas deficientes nas vagas reservadas.

${ }^{4}$ Decreto $6.096 / 2007$.

${ }^{5}$ A estratégia 12.16 PNE atualiza o preceituado nas Portarias: "consolidar processos seletivos nacionais e regionais para acesso à Educação superior como forma de superar exames vestibulares isolados".

${ }^{6}$ Chamado "SiSU de inverno". Não ocorre em todas as instituições.

${ }^{7}$ Em primorosa revisão de literatura sobre o SiSU (ARIOVALDO e NOGUEIRA, 2018), foram subdivididos três grupos, permeáveis entre si: o primeiro se dedica mais diretamente 
às mudanças no processo de tomada de decisão pelos candidatos durante o processo de seleção, ressaltando seu impacto sobre a escolha dos cursos superiores. O segundo focaliza os efeitos do SiSU na ocupação das vagas, incluindo os fenômenos da mobilidade geográfica, da permanência e da evasão nos cursos e instituições. $O$ terceiro analisa os possíveis efeitos democratizantes do SiSU, aquilatando em que medida esse novo sistema teria facilitado o acesso de grupos subrepresentados na educação superior.

${ }^{8} \mathrm{O}$ que nos obriga à seguinte indagação: para onde estarão indo os candidatos menos competitivos?

${ }^{9}$ A percepção popular sobre um certo efeito elitizante do SISU já se faz notar. Morais (2016) demonstra que pré-vestibulares comunitários do Rio de Janeiro têm orientado seus alunos a concorrerem para a Universidade Estadual do Rio de Janeiro (UERJ), que pratica um vestibular próprio, em detrimento das universidades federais, dado que nestas a concorrência é entre os "melhores do país" e não do estado ou da cidade.

${ }^{10}$ Quando o termo evasão é enunciado pelos autores citados, não especificamos a visão que possuem do fenômeno. Quando o empregamos autoralmente, entendemos por evasão a saída da instituição ou do sistema, uma vez que estamos enfrentando o problema das sucessivas chamadas para ingresso e a ociosidade de vagas nas instituições e, por consequência, do sistema.

${ }^{11}$ No caso das instituições federais, o REUNI já incluía entre seus objetivos "criar condições para a ampliação do acesso e permanência na educação superior, no nível de graduação" e, dentre suas diretrizes, apontava a "redução das taxas de evasão e a ampliação de políticas de inclusão e assistência estudantil”.

12 “(...) mensuram a movimentação dos discentes entre períodos letivos subsequentes, permitindo o cálculo de indicadores de fluxo ou trajetória educacional, além de expressarem relações entre rendimento escolar do aluno e sua trajetória em um determinado nível educacional, sua movimentação entre unidades educacionais integrantes do respectivo sistema de ensino, ou a interrupção prematura dessa trajetória (antes da conclusão esperada do respectivo nível de ensino)" (INEP, 2017, p. 7).

${ }^{13} 164$ mil vagas, segundo o MEC.

${ }^{14}$ Ressaltamos que o processo de interiorização não é trivial. Deve estender um bem público de natureza complexa, que demanda a multiplicação de infraestrutura, pessoal docente e técnica, setores de apoio, como laboratórios e bibliotecas, em locais desprovidos ou com baixa oferta desses atributos. Nesse sentido, a interiorização pela via do REUNI caminha na direção oposta ao surgimento da quase totalidade das IFES em sua sede, que ocorria por consolidação e junção de escolas preexistentes. Ou seja: o processo de interiorização das IFES parte de um relativo vácuo, tornando o desafio considerável. Em muitas localidades este vácuo se manifesta na precariedade de instalações, recursos, oferta de estágios, e nesse caso não importará a adequação de curso e de instituição, se as condições de oferta frustrarem o estudante. (VARGAS, 2016).

${ }^{15}$ A despeito do preconizado no art. 4o do Decreto do REUNI: "respeitada a vocação de cada instituição e o princípio da autonomia universitária, deverá indicar a estratégia e as etapas para a realização dos objetivos referidos no Decreto".

${ }^{16}$ Ação de Descumprimento de Preceito Constitucional proposta pelo partido em 2009. 
${ }^{17}$ Tais bônus são adotados por outras IFES, como a Universidade Federal do Pará e o Centro Universitário São José-SC (VARGAS, 2016).

${ }^{18}$ Sobre esse ponto, não ignoremos o momento de inflexão política que atravessamos, que pode produzir resultados ainda mais adversos em relação à autonomia universitária.

${ }^{19}$ Li (2016) demonstra, em nível nacional, que a fruição de assistência estudantil pelo estudante diminui as chances de evasão. Saccaro (2016) confirma que a evasão é menor entre estudantes que receberam Bolsa Permanência do Programa Nacional de Assistência Estudantil, realizando uma avaliação da relação custo-benefício dos programas de bolsa e os resultados em permanência. Refere que "a política se mostra importante para a permanência de estudantes de famílias menos abastadas no ensino superior, uma vez que o sistema de cotas e aumento de vagas podem ser medidas incipientes para o aumento do número de pessoas com ensino superior" (SACCARO, 2016, p. 52). É exatamente o que verificam Cardoso e Vargas (2015), em estudo sobre o perfil socioeconômico de ingressantes e concluintes de uma IFES: o perfil dos concluintes é mais elevado que o dos ingressantes.

${ }^{20}$ Por exemplo, Bardella e Sotomayor (2014), em trabalho sobre a forma de distribuição de vagas realizada pela Associação Nacional dos Centros de Pós-Graduação em Economia, mostram as sucessivas alterações do sistema, com foco no ajuste da seleção entre candidatos e cursos.

21 "Represando e distribuindo distinção: a barragem do ensino superior" (VARGAS, 2008).

${ }^{22}$ Desigualdade maximamente mantida (Maximally Maintained Inequality - MMI), proposta por Hout e Raftery e desigualdade efetivamente mantida (Effecively Maintained Inequality - EMI) proposta por Lucas (HOUT e RAFTERY e LUCAS apud VARGAS, 2008). A primeira aponta a permanência da desigualdade educacional mesmo com a expansão educacional, na medida em que os melhor aquinhoados socialmente são os primeiros a ocupar e talvez a esgotar as novas chances. Tal efeito só não ocorreria em caso de universalização do nível de ensino. A segunda ressalta que outras dimensões presentes dentro da estrutura social contribuem para a manutenção das desigualdades educacionais, como no caso da escolha dos cursos e instituições. Ou seja: passa a existir a possibilidade de inserção no sistema, mas não nas suas primeiras fileiras.

${ }^{23}$ A Olimpíada Brasileira de Matemática das Escolas Públicas é aplicada anualmente para alunos do $6^{\circ}$ ano do fundamental ao $3^{\circ}$ ano do ensino médio de escolas públicas. São cerca de 18 milhões de inscritos, de 47 mil escolas, em 99\% dos municípios brasileiros. O Bolsa Família é um programa de transferência direta de renda, direcionado a famílias em situação de pobreza e de extrema pobreza em todo o País. Famílias extremamente pobres possuem renda mensal de até $R \$ 89,01$ por pessoa. Famílias pobres têm renda mensal entre $R \$ 89,01$ e R \$ 178,00 por pessoa. Disponível em: http:/ /www.caixa.gov.br/programas-sociais/bolsafamilia/Paginas/default.aspx. Acesso em 18/09/2018.

Submetido: $04 / 10 / 2018$

Aprovado: 19/11/2018

Contato:

Rua Negreiros Lobato, n. 23, ap. 103, Lagoa

Rio de Janeiro | UF | Brasil

CEP 22.471-130 